and the right of the general public to good health.? Nevertheless, in exceptional cases statutory intervention may be justified, but the present system may have failed to find the correct balance between the rights of the public and those of infected people.

The selective application of certain sections of the Public Health Act 1984 to HIV demonstrates a piecemeal approach to the development of the law. The act still contains many features which have endured from the great Public Health Act of 1875, based on robust utilitarian principles that were designed to deal with highly infectious diseases in emergency situations. It shows little concern for human rights or the principle of self determination. For example, compulsory examination may be justified if "it is in his (the infected person's) own interest or in the interest of his family or in the public interest."

Modern regimes of coercive medicine, such as the Mental Health Act 1983, contain a system of appeals and checks and balances to guard against potential abuse. Public health medicine has a strong tradition of utilitarian precepts and easily lapses into an uncritical, paternalistic philosophy. This anachronistic approach undermines the acceptability of the powers under the Public Health Act and also the National Assistance Acts. ${ }^{9}$ If powers of compulsion are to be maintained they must meet the standards of contemporary society.

The underlying assumption of modern legislation is that individuals are best placed to judge their own interests; the paternalism of the existing public health provisions is no longer appropriate. Only the threat to other members of society is usually thought to justify coercion, and where compulsion is necessary it must be exercised through fair procedures. The victim must be entitled to argue against the use of such powers, if possible before they are exercised, but if urgent action has been necessary the use of powers should be challengeable through appeal. Another example, taken from the Mental Health Act model, would be the dilution of the power of individual doctors by requiring consultation with other professionals.

The repeated consolidation of the old law withou major reform has resulted in a Public Health Act that is unable to adapt to its current role and is unfit for the new demands likely to be placed on it. In 1989 the Department of Health produced a thorough and welcome consultation document inviting views on possible changes to the law on infectious disease control in England and Wales. ${ }^{10}$ Given the contentious and non-consensual nature of the provisions contained in the current legislation and their consequences for the liberty of individuals, a comprehensive revision of the existing law is called for.

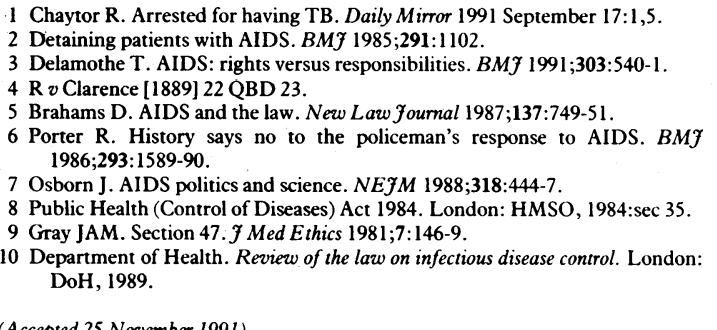

\title{
Public opinion, the NHS, and the media: changing patterns and perspectives
}

\author{
Ken Judge, Michael Solomon, David Miller, Greg Philo
}

The National Health Service has been at or close to the top of the political agenda since the summer of 1987 . One consequence has been a plethora of polls and surveys seeking to elicit the public's views about many different aspects of the health care system. Public opinion about the NHS is now thought to be a key political indicator, but its interpretation is fraught with difficulty.

Our first aim in this paper is to review trends in public opinion during the 1980s. We show how the reporting of the public's perceptions can be influenced by methodological issues such as the wording of questions and the context in which they are asked. Secondly, we present new data collected by the Office of Population Censuses and Surveys omnibus surveys and the University of Glasgow Media Group on behalf of the King's Fund. These data indicate how media coverage of the NHS in the last quarter of 1991 might have been related to changes in public opinion. Finally, we consider the possibility that public dissatisfaction with the NHS may have peaked in 1990.

BMF 1992;304:892-5

The latest figures on public attitudes indicate an increase in dissatisfaction with how the NHS is run. We do not attach any great significance to this, since, as we will argue, there are fluctuations in opinion which seem to relate to the changing media agenda and to the reflection by the media of political debate.

\section{Trends}

Two series of surveys over recent years have explored attitudes to the NHS.

\section{BRITISH SOCIAL ATTITUDES SURVEYS, 1983-90}

The British Social Attitudes survey regularly asks people about their levels of satisfaction with the NHS in general and with specific services in particular. Respondents are usually asked: "All in all, how satisfied or dissatisfied would you say you are with the way in which the National Health Service runs nowadays?" Table I shows that between 1983 and 1990 the proportion reporting dissatisfaction increased from a quarter to almost a half.

The general question about the NHS is usually followed by more specific questions concerning satisfaction with particular aspects of the health service. Respondents are asked: "From your own experience, or from what you have heard, please say how satisfied or dissatisfied you are with the way in which each of these parts of the National Health Service runs nowadays."

Table II shows that most dissatisfaction was expressed in relation to hospitals. While relatively low levels of dissatisfaction with other areas of the health

Numbers are percentages of people $\dagger$

\begin{tabular}{lcccccc}
\hline Response & $\begin{array}{c}1983 \\
(\mathrm{n}=1761)\end{array}$ & $\begin{array}{c}1984 \\
(\mathrm{n}=1675)\end{array}$ & $\begin{array}{c}1986 \\
(\mathrm{n}=3100)\end{array}$ & $\begin{array}{c}1987 \\
(\mathrm{n}=2847)\end{array}$ & $\begin{array}{c}1989 \\
(\mathrm{n}=3029)\end{array}$ & $\begin{array}{c}1990 \\
(\mathrm{n}=2797)\end{array}$ \\
\hline Satisfied (very or quite) & 55 & 51 & 40 & 41 & 36 & 37 \\
Neither & 20 & 19 & 19 & 20 & 18 & 15 \\
Dissatisfied (very or quite) & 25 & 30 & 39 & 39 & 46 & 47 \\
\hline
\end{tabular}

Source: British. Social Attitudes Surveys.

$\star$ The question was not asked in the 1985 survey; there was no survey in 1988 .

tThe percentages do not total 100 due to rounding up or down. 
TABLE II - Percentages of respondents in British social attitudes surveys quite or very dissatisfied with various parts of $N H S$

\begin{tabular}{lccccc}
\hline Service & $\begin{array}{c}1983 \\
(\mathbf{n}=1761)\end{array}$ & $\begin{array}{c}1986 \\
(\mathbf{n}=3100)\end{array}$ & $\begin{array}{c}1987 \\
(\mathbf{n}=2847)\end{array}$ & $\begin{array}{c}1989 \\
(\mathbf{n}=3029)\end{array}$ & $\begin{array}{c}1990 \\
(\mathbf{n}=2797)\end{array}$ \\
\hline General practitioners & 13 & 14 & 13 & 12 & 11 \\
NHS dentists & 10 & 10 & 9 & 11 & 11 \\
Health visitors & 6 & 8 & 8 & 8 & 8 \\
District nurses & 2 & 3 & 3 & 4 & 4 \\
Hospital inpatient & 7 & 13 & 13 & 15 & 15 \\
Hospital outpatient & 21 & 29 & 29 & 30 & 28 \\
\hline
\end{tabular}

TABLE III-Respondents' overall opinion of NHS in their area in National Association of Health Authorities and Trusts surveys, 1985-91. Numbers are percentages of people

\begin{tabular}{lccccccc}
\hline Response & $\begin{array}{c}1985 \\
(\mathbf{n}=1509)\end{array}$ & $\begin{array}{c}1986 \\
(\mathbf{n}=1515)\end{array}$ & $\begin{array}{c}1987 \\
(\mathbf{n}=1508)\end{array}$ & $\begin{array}{c}1988 \\
(\mathbf{n}=1552)\end{array}$ & $\begin{array}{c}1989 \\
(\mathbf{n}=1869)\end{array}$ & $\begin{array}{c}1990 \\
(\mathbf{n}=1926)\end{array}$ & $\begin{array}{c}1991 \\
(\mathbf{n}=2020)\end{array}$ \\
\hline Positive & 77 & 75 & 76 & 67 & 72 & 65 & 75 \\
Neither & 12 & 10 & 8 & 10 & 9 & 13 & 8 \\
Negative & 10 & 11 & 13 & 17 & 16 & 17 & 12 \\
Don't know & 1 & 3 & 3 & 5 & 3 & 4 & 5 \\
\hline
\end{tabular}

${ }^{\star}$ Do not total 100 due to rounding up or down.

service remained constant during the 1980 s, the proportion expressing dissatisfaction with outpatient services rose by a third, and the proportion dissatisfied with inpatient services doubled. Most notable is the high absolute level of dissatisfaction with hospital outpatient attendance, with almost $30 \%$ of respondents expressing dissatisfaction consistently since 1986.

Nevertheless, dissatisfaction with specific services, even hospital outpatient attendance, was less pronounced than that with the running of the NHS as a whole. One explanation is that respondents reply to questions about specific health services primarily on the basis of their own experience. This is supported by the fact that nearly a half of respondents consistently give no opinion about health visitors and district nurses, presumably because they have no experience of using these services. In contrast, the NHS as an institution is a more politicised issue, about which many people's views will be influenced by their social attitudes and by the media.

NATIONAL ASSOCIATION OF HEALTH AUTHORITIES AND TRUSTS SURVEYS, 1985-91

Since 1985 the National Association of Health Authorities and Trusts has commissioned polling organisations to conduct an annual survey in Britain of people's views concerning the NHS. The first question always asks: "What is your overall opinion of the National Health Service in your area?"

Table III shows that in $1985,10 \%$ of the sample reported negative opinions of the NHS in their area. In 1988 this figure rose to $17 \%$; it remained at about $17 \%$ until 1991 , when it fell to $12 \%$.

The second question asks those who have attended hospital in the past two years: "Thinking about the last time you yourself attended hospital, how satisfied were you with the treatment you received?"

Replies have revealed consistently high levels of satisfaction, with between $84 \%$ and $87 \%$ of people since 1985 stating that they were satisfied with hospital treatment. This supports the finding in the British social attitudes surveys that dissatisfaction with specific health services is much lower than with the NHS as a whole.

\section{Comparisons between the surveys}

Both types of survey show increasing levels of dissatisfaction with the NHS as an institution during the 1980s up to and including 1990. However, there are some important differences as well as other similarities.

\section{DIFFERENCES}

The most obvious difference between the surveys is that between $10 \%$ and $17 \%$ of respondents in National Association of Health Authorities and Trust surveys expressed negative opinions about the NHS, whereas between $25 \%$ and $47 \%$ in the British social attitudes surveys reported dissatisfaction with the running of the NHS.

One possible reason for this difference is the wording of the questions. The association's surveys ask for "your overall opinion of the NHS in your area." This is not the same as eliciting "satisfaction with the way the NHS runs," as in the social attitudes surveys, which concentrates on the actual running of the NHS, and asks for a more politicised opinion on the basis of experience "or from what you have heard." In contrast, the association's question, while not divorced from other considerations, is more firmly grounded in local knowledge and experience.

SIMILARITIES

One of the similarities between the two types of survey is the difference in responses to general and specific questions about health services. When people are asked about satisfaction with specific services, positive responses predominate in all surveys. However, if they are asked to express a value judgment on the running of the NHS, whether nationally or locally, relatively more replies are negative.

Another similarity is the consistent gradient in dissatisfaction reported across different aspects of the NHS. Least discontent was expressed in relation to general practitioner services, while the highest levels of dissatisfaction were in relation to outpatient services. A recent report by the National Audit Office identified several outstanding problems in outpatient management. ${ }^{1}$ Public dissatisfaction was greatest with lengthy waiting times, inadequate information for patients, and uncomfortable waiting areas with poor facilities.

An alternative explanation of variable levels of satisfaction with different parts of the NHS is that people may feel more comfortable in expressing dissatisfaction with services which are seen as less personal and more organisational, such as waiting times for outpatient appointments.

\section{METHODOLOGICAL IMPLICATIONS}

One clear implication of the discussion above is that methodological considerations such as the precise wording of questions can influence the interpretation of public opinion data. In addition, the influence of context and order of the questions is well documented both in general terms ${ }^{23}$ and more specifically regarding health issues. ${ }^{4-6}$

The importance of these considerations can be shown quite clearly. The association's surveys always begin by asking for opinions about the NHS locally. In contrast, the social attitudes surveys always contain a selection of questions concerning priorities for government policy and public expenditure before asking specifically about the NHS. It seems probable that the variation in wording and context is the most likely explanation of the observed differences in support for the NHS. ${ }^{7}$ This view is supported by evidence from a survey of four health districts, ${ }^{8}$ and by more recent national data described below.

\section{Omnibus surveys, 1991-2}

As part of a more detailed investigation of public opinion about the NHS, the King's Fund commissioned the Office of Population Censuses and Surveys to include in some of their monthly omnibus surveys questions about aspects of the NHS with which people are most dissatisfied and about which particular services are felt to be most in need of improvement.

The omnibus surveys of August and November 1991 
and February 1992 included identical questions about satisfaction with the NHS to those used in the social attitudes surveys. A more detailed account of the findings of the first two surveys can be found elsewhere. ${ }^{9}$ Table IV shows a fluctuating pattern of responses, with the highest levels of dissatisfaction in the summer of 1991.

TABLE IV - Percentage of respondents in Office of Population Censuses and Surveys omnibus surveys, 19912, quite or very dissatisfied with NHS and various parts of it

\begin{tabular}{lccc}
\hline Service & $\begin{array}{c}\text { August 1991 } \\
(\mathbf{n}=2110)\end{array}$ & $\begin{array}{c}\text { November 1991 } \\
(\mathbf{n}=2091)\end{array}$ & $\begin{array}{c}\text { February 1992 } \\
(\mathbf{n}=2165)\end{array}$ \\
\hline NHS & $25 \cdot 2$ & $17 \cdot 6$ & $19 \cdot 3$ \\
General practitioners & $6 \cdot 7$ & $7 \cdot 9$ & $8 \cdot 3$ \\
Being in hospital as an inpatient & $10 \cdot 0$ & $8 \cdot 3$ & $9 \cdot 9$ \\
Attending hospital as an outpatient & $21 \cdot 9$ & $16 \cdot 7$ & $18 \cdot 3$ \\
\hline
\end{tabular}

Given that the questions were asked in a health care context, immediately after references to state of health and utilisation of services, it is not surprising that the levels of dissatisfaction were much lower than those reported in the social attitudes surveys. It should also be noted, however, that the hierarchy of dissatisfaction shown in both the social attitudes and the association's surveys reappears. Negative opinions of the NHS as a whole were more common than for any particular service, and dissatisfaction with hospital outpatient services far exceeded that associated with general practitioners.

One result particularly worth exploring is the significant fall in dissatisfaction with the NHS between August and November $1991(\mathrm{p}<0.01)$. It could be speculated that this adds support to the interpretation of the change reported in the association's 1991 survey. More generally, these shifts of opinion may be associated with changes in the political debate over the NHS as it was presented by the media during 1991 . We can examine this by drawing on the results of detailed monitoring of the national media which took place over a four week period in both August and November 1991, to coincide with simultaneous surveys of public opinion.

\section{Media coverage}

The media coverage of the NHS in August was limited due to other world events. Two main areas covered were the government's announcement of the second wave of hospitals opting out and the corresponding launch of the counterproposals of the opposition parties, and the debate over waiting lists.

During September and October several issues remained in the public domain. Debates over waiting lists and times, "privatisation," the patient's charter, and the second wave of hospitals opting out received most attention in the national press and on television.

There was more than double the press coverage of the NHS in November than in August. The most common theme was the progress of the NHS reforms, while another prominent concern again was the size of waiting lists. In contrast with the coverage in August, however, waiting lists were commonly discussed in the context of the government's new flagship, the patient's charter. In addition, the chancellor's autumn statement on 7 November received much attention, and while it provoked a mixed reaction, it did have the effect of providing the context for subsequent debate.

\section{Discussion}

For the past five years there has been an unprecedented level of interest in public opinion about the NHS. Unfortunately, curiosity does not necessarily lead to greater clarity about what the reported views of citizens and consumers of health care actually represent. Findings of surveys have been seized and used with rather more alacrity than accuracy. The fact is that great care must be taken when interpreting the results of public opinion surveys. Given this caution, however, the latest evidence from the National Association of Health Authorities and Trusts suggests that public dissatisfaction with the NHS reached a peak in 1990. Whether or not this is a temporary phenomenon remains to be seen.

\section{SHIFTING PERCEPTIONS}

The intensity of debate and its media coverage in the last few months of 1991 were considerable. Nevertheless, such concentrated coverage has not necessarily meant a heightened sense of "panic" in the media. Rather, the coverage has appeared to be mixed. The government seemed to have regained ground in terms of political initiative and media attention during 1991, shifting the terms of debate from negative worrying concerns to more mixed discussion and evaluation of government policy. Television coverage in particular trod a careful line and was neither straightforwardly positive for the government or the opposition.

It seems that the implementation of the NHS reforms has shifted the focus of much debate away from cancelled operations and deaths caused by cuts to the progress of the reforms and whether they are working. The appearance that the government is doing something about the NHS has meant that discussion has tended to focus on the outcome of the reforms. In particular, the controversy over waiting lists in August became subsumed under the discussion of the patient's charter three months later. With the charter and the chancellor's autumn statement the government achieved some success in shifting the media agenda away from potentially damaging generalised concerns towards evaluating specific policies.

It may be that subtle changes in media coverage contributed to displacing anxiety about the NHS from its position in the agenda of public consciousness. This may account for the fall in numbers of those dissatisfied with the running of the NHS between August and November 1991. Another cause of shifting perceptions might have been the change in political leadership. A MORI poll in 1989 found that $67 \%$ disagreed that the NHS was safe in Margaret Thatcher's hands, compared with 53\% for John Major in November $1991 .^{10}$

\section{CARE IN INTERPRETATION}

An apparent fall in dissatisfaction with the way the NHS runs must, however, be carefully interpreted. There is an inherent ambiguity in the question on satisfaction with the NHS. It elicits some combination of political views and personal experience, together with many other factors. Most importantly, perhaps, changes in public opinion may well be seen to reflect the effectiveness of management of news by the various interest groups.

It is important to attempt to interpret what expressions of public opinion may really mean. The social attitudes surveys have consistently found that "the NHS receives overwhelming support as the service most urgently in need of extra resources." international context, "health is now a higher spending priority in Britain than in the United States or Canada." "12 Even during a period of rising dissatisfaction with the NHS, Klein's mid-1980s claim that "there is no sign of decline in support for the NHS as an institution"13 is still a plausible one.

It is tempting to see this enduring loyalty to the NHS as the foundation of public opinion. What can be stated with more assurance, however, is that when asked about the NHS in a less politicised context people continue to express high levels of satisfaction, although 
dissatisfaction with outpatient services continues to be the principal source of concern.

\section{CONCLUSIONS}

In summary, we argue that attitudes derive from complex sets of factors which include actual experience of using health services. But opinion can also be crucially affected by political and peer group cultures. The media can also influence apparent levels of public concern by highlighting specific issues in relation to care or by focusing on other areas such as the efficient use of resources. Such "floating" attitudinal changes might be seen as relatively marginal, accounting probably for less than 10 percentage points. But none the less, they do appear as significant changes and indicate that the media has some power to influence agendas of public concern.

The exact nature of the relation is very complex, and in future work we will investigate these links more fully. We will also explore the relative importance of respondents' demographic and socioeconomic characteristics as well as their self reported state of health and recent experience of health services in determining dissatisfaction with the NHS.

Material from the omnibus surveys was made available through the Office of Population Censuses and Surveys and was used by permission of the Controller of Her Majesty's Stationery Office. We thank Jacqueline Reilly and Leslie Henderson for monitoring media output and John Appleby, Peter Taylor-Gooby, and colleagues in the King's Fund Institute for comments on an earlier draft.

1 National Audit Office. NHS outpatient services. London: HMSO, 1991 2 Schuman H, Presser S. Questions and answers in attitude surveys: experiments on question form, wording and context. New York: Academic Press, 1981.

3 Sigelman L. Question-order effects. In: Singer E, Presser S, eds. Survey research methods: a reader. Chicago: University of Chicago Press, 1989.

4 Blendon RJ, Donelan K. Interpreting public opinion surveys. Health Affairs 1991; 10:166-9.

5 Jaiich-Toth C, Roper BW. Americans' views on health care: a study in contradictions. Health Affairs 1990;9:149-57.

6 Jajich-Toth C, Roper BW. Basing policy on survey data: proceed with caution. Health Affairs 1991;10:170-2.

7 Bosanquet N. An ailing state of national health. In: Jowell R, Witherspoon S, Brook L, eds. British social attitudes: the 5th report. London: Social and Community Planning Research, 1988.

8 Prescott-Clarke P, Brooks T, Machray C. Focus on health care: surveying the public in four health districts. London: Social and Community Planning Research and Royal Institute of Public Administration, 1988.

9 Solomon M. Public opinion and the National Health Service. Health Care UK 1991:73-7.

10 Market Opinion Research International. The future of the NHS. British Public Opinion. London: MORI, November 1991.

11 Taylor-Gooby P. Social welfare: the unkindest cuts. In: Jowell R, Witherspoon S, Brook L, eds. British social attitudes: the 7th report. London: Social and Community Planning Research, 1990.

12 Blendon RJ, Donelan K. British public opinion on National Health Service reform. Health Affairs 1989;8:52-62.

13 Klein R. Why Britain's conservatives support a socialist health care system. Health Affairs 1985;4:41-58.

(Accepted 19 March 1992)

\section{Health policies in the 1992 general election}

We sent each of the three main party spokesmen on health a set of questions about their health policies. These were largely drawn from the BMA's health strategy document "Leading for Health" and covered longer term issues as well as more immediate ones. We have compiled the following answers from their replies or, in the case of the Labour Party (which did not reply), from its manifesto and health "white paper."

\section{Improving the health of the people}

Conservatives refer to their green paper, the Health of the Nation, and promise a white paper identifying specific targets. "It will be the first time that England has had an explicit, rational, and coherent strategy for improving the health of its population."

Labour will launch a National Health Initiative to promote physical and mental health from birth to old age. They will set new targets to cut inequalities in health between social classes and ethnic groups. They will ban tobacco advertising, encourage healthy diets by labelling food better, and create an NHS occupational health service.

Liberal Democrats "lay great stress on the need for a comprehensive strategy for health promotion" and will ensure that opportunities are created for people to become and remain healthy.

Health and community services: free, comprehensive, accessible, with equal standards, and freedom of choice for patients?

Conservatives-The NHS will continue to meet the "demands placed on it through a free hospital and GP service, equally accessible to everybody." They do not plan new charges. Mr Waldegrave wants to see all parts of the NHS raised to the standards of the best. "We have improved choice in certain respects, for example by making it easier to change GP.... Contracts which reflect the views of local GPs and residents are the main guarantee of a service which meets their needs and wishes."

Labour will restore free eye tests and introduce no new charges to keep the health service free at the point of use. The objective of a national service is to ensure that local provision meets an acceptable national standard. Labour's plans for ensuring fairness in the delivery of care will include setting targets for improving access for sections of the community who are currently getting a less good deal. It will "restore the right of patients to be treated in the hospital of their choice; women will have the right to be seen by a woman GP."
Liberal Democrats will abolish charges for eye tests and dental check ups and freeze remaining charges with a view to reducing them. Their patient's charter will give the right to information, to choice of GP, to participate in decisions, to dignified and timely treatment, and to "no fault" compensation for medical accidents.

\section{Ensuring that public bodies adopt policies that promote health}

Conservatives - "Action for everybody" is a key theme; all departments are signed up to the strategy, and a coordinating ministerial group, encompassing 14 departments, ensures that health promotion is on the agenda across Whitehall.

Labour's health initiative will be led by the Department of Health and Community Care and by a new cabinet committee that will "cut through departmental boundaries."

Liberal Democrats will require central government and other public bodies to assess the impact of their own policies on health, measuring agreed indicators and targets within their policy area. In particular, they will ban promotion of tobacco, set stricter standards of water purity and food hygiene, take tough action against pollution, and use fiscal policy to promote good health. As well as taxing tobacco and alcohol they will remove VAT from housing repairs and renewals.

\section{Funding the NHS}

Conservatives will "year by year increase the level of real resources committed to the NHS and efficiency savings will be ploughed back into the Service.... Since 1987 we have maintained an annual average increase in NHS spending of $3.6 \%$ above inflation."

Labour will make at least $£ 1$ bn available over the first 22 months. It will fully fund pay awards, abolish tax relief on medical insurance, and use the $160 \mathrm{~m}$ to modernise cancer services.

Liberal Democrats believe that funding is the crucial issue and have three groups of priorities. Firstly, they 